\title{
Instructional Model of Japanese Science Teachers for the Gifted
}

\author{
Takekuni Yamaoka $^{1,2, *}$, Shinji Matsumoto ${ }^{3}$, Manabu Sumida ${ }^{4}$ \\ ${ }^{1}$ Kitauwa Upper Secondary School, Japan \\ ${ }^{2}$ The Joint Graduate School in Science of School Education, Hyogo University of Teacher Education, Japan \\ ${ }^{3}$ Hyogo University of Teacher Education, Japan \\ ${ }^{4}$ Faculty of Education, Ehime University, Japan \\ *Corresponding author: yamaoka.takek@gmail.com
}

Received May 31, 2015; Revised June 20, 2015; Accepted July 01, 2015

\begin{abstract}
The purpose of this study was to investigate the instructional model used by Japanese science teachers for mentoring gifted students. A total of thirty teachers were interviewed about the characteristics of his/her students who achieved excellent results in a science contest and about his/her instructional strategies for the students. The subjects include 27 high school science teachers and 3 elementary teachers; 29 out of the 30 are male and 27 have more than 10 years teaching experience. The interviews were conducted between July 2008 and August 2009 in Ehime, Ibaraki, Tokyo, and Okayama, Japan. Each teacher was interviewed for an average of 30 minutes. Interview transcripts were used in the data analysis. The results of the text analysis extracted some phrases that commonly described science instruction, specifically: (1) at first, themes were not given to the students; (2) opportunities for appropriate advice and coaching were needed; (3) teachers should continue to study; (4) originality was appreciated; (5) the process and experiences were more important than the results themselves; (6) teachers helped students to acquire basic understanding and skills; (7) students found study/research similar to play; (8) students established good networks with experts in a specific area; (9) teachers enjoy teaching gifted students science very much; (10) students were asked to design their own research; (11) students were asked to make things; and (12) students developed the habit of recording what they thought and found in everyday life. Finally, an instructional model for Japanese science teachers who teach gifted students is proposed on the basis of these results.
\end{abstract}

Keywords: Japanese science teachers, Instructional model for gifted students, Science contests, text mining

Cite This Article: Takekuni Yamaoka, Shinji Matsumoto, and Manabu Sumida, "Instructional Model of Japanese Science Teachers for the Gifted.” American Journal of Educational Research, vol. 3, no. 7 (2015): 944948. doi: 10.12691/education-3-7-19.

\section{Introduction}

In the Japanese Fundamentals of Education Act, the extension of personal respect and capabilities has been advocated as one of its fundamental principles [1]. Nevertheless, the problem seems to lie in the fact that the education system is inadequate at motivating intellectual interest and developing the abilities of students. As an exceptional case, particularly among the developed nations, in postwar Japan, equal education is advocated, and special education for gifted and talented students does not exist [2]. In Japan, places of education are expected to respond to the wide variety of students' educational needs adequately and flexibly, and to utilize appropriate methods and measures, depending on the needs of individual students.

Virtually none of the education systems in post-war Japan could accomplish all these goals. Efforts toward responding to the variety of students' needs were not completely absent, however. As a specific example, classes in Japanese schools are organized according to ability. In another representative example, students in
Japan earn good results in science competitions. In particular, the Japan Student Science Award (JSSA) is known as one of the most respected science prizes, with a rich tradition in the country. The competition has a history of about 60 years and has been conducted every year for junior and senior high school students [3].

In Japan, the direction of science and technology innovation policy is determined by the Science and Technology Basic Plan, which is formulated every five years. In the third Science and Technology Basic Plan that was approved by the Cabinet in 2006, the phrase "extension of the personality and abilities of talented children" was used for the first time [4]. It resulted in the expansion of support systems, such as high schools, that emphasize science and mathematics education. In addition, it has promoted talented Japanese students' participation in various international science and technology contests. In the fourth Science and Technology Basic Plan that was approved by the Cabinet in 2011, the aforementioned plans were continued [5]. In particular, the specific national policy of "development of human resources for the next generation" further enhanced support for the Super Science High School. In addition, this policy has 
promoted the expansion of other school achievements. And, it aims to strengthen interest in science and technology and to promote young peoples' interest in science, by: (1) increasing the number of students who participate in an International Science Olympiad; (2) extending the talent of students; (3) implementing the Science Koshien, Science Inter College Award; and so forth.

At the same time, the Japan Science and Technology Agency (JST) were examined by instantiating the Gifted Education Subcommittee in 2009. In 2010, the Gifted Education Subcommittee report, "Founding a nascent talent to support science and technology innovation," was published [6]. In this report, there is an item called "Toward the challenges and solutions of Gifted Education." In this item, the following points have been cited as problems: (1) in compulsory subject classes for elementary, middle and high school students, there is not enough tutorial teaching or content that is individualized for learners according to their levels of understanding; (2) it is not sufficient for science teachers to have specific experience with leadership on research projects and other activities of scientific inquiry; and so on. In Japan, there is an urgent need to propose instructional models that may guide individualized learning for gifted students.

In this study, we will discuss how we fostered the work of gifted students who were full of intellectual curiosity. Our focus will be on teachers who guided students toward excellent results in science contests. This study aims to illuminate the factors that lead to success, and make teachers and gifted students "tick." The main objective of this study is the construction of an instructional model that can be used to evaluate a variety of students' talents. This objective will be met through extraction of data from a case study.

In Japan, the established senior high school course of science study is called "Science Project Study." The science teacher is expected to take appropriate measures corresponding students' individual needs. From this perspective, the construction of the above instructional model is very important.

\section{Materials and Methods}

\subsection{Subjects of Analysis}

The purpose of this study was to investigate the instructional model used by Japanese science teachers for mentoring gifted students. This study investigates the development of gifted students who were full of intellectual curiosity. We conducted interviews with teachers who guided a student to excellent results in a science contest. A total of thirty teachers were interviewed about the characteristics of their students who attained excellent results in a science contest, and about their instructional strategies for the students. The subjects include 27 high school science teachers and 3 elementary teachers; 29 out of the 30 are male and 27 have more than 10 years teaching experience. The interviews were conducted between July 2008 and August 2009 in Ehime, Ibaraki, Tokyo, and Okayama, Japan.

\subsection{Process of Analysis}

In this study, excellent practitioners who guided gifted students will be discussed. Using the checklist of gifted behavior proposed by Sumida [7], this study created the interview content about both gifted students, and teachers who guided the gifted students. Each teacher was interviewed for an average of 30 minutes. Transcripts of the interviews were used in the data analysis.

We made use of an IC recorder with the permission of the interviewee. All recorded data that were transcribed as text were analyzed. From now on, "All recorded data that were transcribed as text data" will be referred to simply as the "utterance protocol." To elucidate the themes found in every utterance protocol, we used techniques of text mining. This study was performed using the text analysis system KH Coder Ver.2. Beta.32 (hereafter, “KH Coder”), as developed by Higuchi [8]. KH Coder uses a method of analyzing a variety of qualitative data, such as text, audio, and video. This method incorporates aggressively specific methods of content analysis, and can perform quantitative analysis of the data [9]. By using $\mathrm{KH}$ Coder, the entire text can be divided into the smallest possible units; as a result, it is possible to extract more word patterns. In this study, word patterns that appeared in interviews were extracted using $\mathrm{KH}$ Coder, and utterance protocols were developed from these results. A classification table was created to organize content that was recognized as having the same meaning across teachers. This classification table was used to extract themes that were common to the 30 science teachers studied, and thus build an instructional model for Japanese Science Teachers of the Gifted.

\section{Results and Discussion}

\subsection{The Contents of the Interview}

In general terms, the interviews contained questions about the following two content areas:

(1) About the student (student model);

About students who are being taught.

(2) About how to teach science (teacher model);

About the teaching and coaching method for the students. Specifically, it is in the following two aspects.

(a) About planning of the experimental design.

(b) About teaching methods.

Examples of these content area questions are shown in Table 1.

\subsection{The Analysis Protocol Using Text Mining}

\subsubsection{Extraction of Word Patterns in the Student Model}

Using KH Coder, the utterance protocol was examined to extract common word patterns. In utterance protocols consisting of content related to the student, characteristic words or word stems were extracted in order of their frequencies. The resulting extracted words, frequencies of use, and actual examples are summarized in Table 2. As a result, it was possible to extract characteristic ideas common to the student model.

\subsubsection{Extraction of Word Patterns in the Teacher Model}

Similar to the student model, in utterance protocols consisting of content related to the teacher, characteristic 
words or word stems were extracted in order of their frequencies. The results for extracted words, frequency of use, and actual examples are shown in Table 3. As a result, it was possible to extract characteristic ideas common to the teacher model.

Table 1. The Content Areas of the Interviews Question items An Actual Example

\begin{tabular}{|c|c|c|}
\hline & Question items & An Actual example \\
\hline \multirow[t]{2}{*}{$\begin{array}{l}\text { (1) Student } \\
\text { Model }\end{array}$} & \multirow[t]{2}{*}{$\begin{array}{l}\text { About students } \\
\text { who are being taught }\end{array}$} & $\begin{array}{l}\text { W What are the characteristics of a recipient of science competition? } \\
\text { ※ About the common characteristics of students who can be awarded the prize. } \\
\text { ○ Have you ever felt it difficult to guide the gifted student? } \\
\text { ※ About a specific example. }\end{array}$ \\
\hline & & ○ How was a novel and serendipitous idea created? \\
\hline \multirow{6}{*}{$\begin{array}{l}\text { (2) Teacher } \\
\text { Model }\end{array}$} & \multirow{3}{*}{$\begin{array}{l}\text { About planning } \\
\text { of the experimental design }\end{array}$} & o Could you tell us about how you determined the research theme of students' scientific work? \\
\hline & & $\begin{array}{l}\text { As a science teacher, how do you intend to guide gifted students to acquire knowledge of the } \\
\text { relevant concepts after the research theme is determined? }\end{array}$ \\
\hline & & $\circ$ How did draw out the novel and serendipitous ideas created? \\
\hline & \multirow{3}{*}{ About teaching methods } & $\circ$ Are there any methods that foster long-term interest in a specific theme or problem? \\
\hline & & $\circ$ Are there any tips on producing good graphs and charts? \\
\hline & & ○ What are you aware of on a daily basis in science classes? \\
\hline
\end{tabular}

Table 2. Extraction of Single-Word Patterns in the Student Model

\begin{tabular}{|c|c|c|}
\hline Extracted word & $\begin{array}{c}\text { Frequency of } \\
\text { word used }\end{array}$ & An Actual example \\
\hline Child & 40 & Childlike \\
\hline Theme & 17 & \multirow{2}{*}{$\begin{array}{l}\text { A theme of study decides by } \\
\text { themselves }\end{array}$} \\
\hline Oneself & 17 & \\
\hline Discussion & 9 & \multirow{2}{*}{$\begin{array}{l}\text { Discussion can be enhanced } \\
\text { and useful opinions can obtain }\end{array}$} \\
\hline Opinions & 4 & \\
\hline Idea & 25 & \multirow{3}{*}{$\begin{array}{l}\text { There are novel and } \\
\text { serendipity idea }\end{array}$} \\
\hline Serendipity & 13 & \\
\hline Novel & 6 & \\
\hline Time & 12 & \multirow{2}{*}{$\begin{array}{l}\text { Tackle something for a long } \\
\text { time }\end{array}$} \\
\hline Work & 8 & \\
\hline Inquiry & 6 & Have a strong mind of inquiry \\
\hline Stubborn & 4 & \multirow{2}{*}{$\begin{array}{l}\text { Stubborn and tenacious } \\
\text { personality }\end{array}$} \\
\hline Tenacious & 4 & \\
\hline
\end{tabular}

\begin{tabular}{|c|c|c|}
\hline Extracted word & $\begin{array}{c}\text { Frequency of } \\
\text { word used }\end{array}$ & An Actual example \\
\hline Theme & 95 & \multirow{2}{*}{$\begin{array}{l}\text { A theme of study is decided } \\
\text { by the student }\end{array}$} \\
\hline Decide & 24 & \\
\hline Interesting & 23 & \multirow{3}{*}{$\begin{array}{l}\text { Recommends an interesting } \\
\text { novel idea }\end{array}$} \\
\hline Idea & 21 & \\
\hline Novel & 6 & \\
\hline Oneself & 14 & \multirow{2}{*}{ Teacher himself to study } \\
\hline Study & 10 & \\
\hline Appropriate & 11 & \multirow{2}{*}{ Give appropriate advice } \\
\hline Advice & 11 & \\
\hline Information & 11 & \multirow{2}{*}{$\begin{array}{l}\text { Collect information from the } \\
\text { university }\end{array}$} \\
\hline University & 9 & \\
\hline Process & 8 & Emphasis on process \\
\hline Foundation & 7 & Take good care the foundation \\
\hline
\end{tabular}

Table 4. Content Classification of Word Patterns

\begin{tabular}{|c|c|}
\hline Instructional Model & Distinctive content that is common to each teacher \\
\hline \multirow{7}{*}{$\begin{array}{l}\text { (1) Student Model; } \\
\text { About the student }\end{array}$} & Aspects of student behavior (e.g., childlike) \\
\hline & Communication skills \\
\hline & The student determines an optimum overall hypothesis from the plurality of overall hypotheses \\
\hline & Student are clear in distinguishing between or among things \\
\hline & Student expends much time and effort on the experiment \\
\hline & Student have too much pride \\
\hline & The student's future aim is clear \\
\hline \multirow{11}{*}{$\begin{array}{l}\text { (2) Teacher Model; } \\
\text { How to teach science }\end{array}$} & The teacher holds a seminar \\
\hline & A subject of study is decided by the student \\
\hline & The teacher always seeks original ideas \\
\hline & Teacher regards a pastime as important \\
\hline & Teacher regards the experimental process as important \\
\hline & Teacher inquires with a specialist \\
\hline & Students were asked to make things \\
\hline & Students were asked to design their own research \\
\hline & Teacher regards fundamental content as important \\
\hline & Students developed the habit of recording what they think and find in everyday life. \\
\hline & The teacher himself works hard in science \\
\hline
\end{tabular}

\subsection{Creating a Classification Table}

As shown in both Tables 2 and 3, many of the word patterns that appeared tended to be used in conjunction with words from other appearing patterns. Thus, to capture multiple-word patterns, we created the content classification table. These results are presented in Table 4. Based on the classification criteria in Table 4, we created a reorganized utterance protocol for all 30 teachers interviewed. Using Table 4, as well as the aggregate frequencies of characteristic words, Table 5 was created. 
In Table 5, the frequently used and characteristic content in utterance protocols is described. Depending on the frequency of use, rankings of the ideas were assigned. Finally, a Japanese science teachers' instructional model for teaching the gifted is proposed on the basis of these results. According to the student model in Table 5, the idea of sparing no effort is ranked first. In other words, it is a given that students who are active in science contests expend a lot of time and effort on their work. Of course, assuming that they complete the work in order to do excellently in science contests, it is quite commonplace for gifted students meet the challenge of science contests with both effort and time. However, many students stay after school for club activities in Japan. Therefore, it is difficult for students in non-science clubs to learn science during the after school club activities. For this practical matter, the teacher model describes key concepts to consider how the teacher should give appropriate guidance.

Table 5. Instructional Model for Japanese Science Teachers of the Gifted

\begin{tabular}{|c|c|c|c|}
\hline Science Education Model & Rank & $\begin{array}{c}\text { Frequency of } \\
\text { word used }\end{array}$ & Characteristic contents \\
\hline \multirow{9}{*}{$\begin{array}{l}\text { (1) Student Model; } \\
\text { Students who are active in } \\
\text { science contests }\end{array}$} & 1 & 19 & Tend to worry too much, but do not mind it \\
\hline & 2 & 8 & Childlike \\
\hline & \multirow{2}{*}{3} & \multirow{2}{*}{7} & Have a good spirit of inquiry \\
\hline & & & Be proud of my job \\
\hline & 5 & 6 & Communication \\
\hline & \multirow{2}{*}{6} & \multirow{2}{*}{5} & Set things right \\
\hline & & & Have an awareness of the issues in daily life \\
\hline & 8 & 3 & Words of encouragement from one's family \\
\hline & 9 & 1 & To set one's sights high \\
\hline \multirow{12}{*}{$\begin{array}{l}\text { (2) Teacher Model; } \\
\text { Teachers' model to support } \\
\text { students who are active in } \\
\text { science contests }\end{array}$} & 1 & 20 & At first themes were not given to the students \\
\hline & 2 & 19 & Opportunities for appropriate advice and coaching were needed \\
\hline & 3 & 16 & Teachers should continue to study \\
\hline & 4 & 15 & Originality was appreciated \\
\hline & 5 & 11 & The process and experience were more important than the results themselves \\
\hline & 6 & 10 & Teachers helped students to completely acquire basic understanding and skills \\
\hline & \multirow{2}{*}{7} & \multirow{2}{*}{7} & Study/research was similar to play for students \\
\hline & & & Students established good network with experts in a specific area \\
\hline & 9 & 6 & Teachers enjoy teaching gifted students science very much \\
\hline & 10 & 5 & Students were asked to design their own research \\
\hline & \multirow[b]{2}{*}{11} & \multirow[b]{2}{*}{4} & Students were asked to make things \\
\hline & & & $\begin{array}{l}\text { Students developed the habit of recording what they thought and found in } \\
\text { everyday life }\end{array}$ \\
\hline
\end{tabular}

For example, teacher model rank item 2 "Opportunities for appropriate advice and coaching were needed," and teacher model rank item 5 "The process and experience were more important than the results themselves," are closely related to each other. Considering these two instructional models, it is possible to construct a system that intuitively anticipates the thought processes of the students.

In addition, teacher model rank item 1 "At first themes were not given to the students," is closely related to the Constructivist Learning Model (CLM). In fact, in the CLM proposed by Robert E. Yager, this is the most basic element [10]. In order to perform teaching and research activities smoothly, it is important that teachers themselves are a focus, such as in teacher model rank item 3 “Teachers should continue to study," and teacher model rank item 9 "Teachers enjoy teaching gifted students science very much.” As a model to the students, teachers themselves affect the students' activities.

Thus, from the findings of this study, in the Instructional Model for Japanese Science Teachers of the Gifted, it is clear that both the activities of students and the awareness of teachers were essential.

\section{Conclusion}

The purpose of this study was to investigate the instructional model used by Japanese science teachers for mentoring gifted students. A total of thirty teachers were interviewed about the characteristics of their students who attained excellent results in a science contest, and about their instructional strategies for the students. The subjects include 27 high school science teachers and 3 elementary teachers; 29 out of the 30 are male and 27 have more than 10 years teaching experience. The interviews were conducted between July 2008 and August 2009 in Ehime, Ibaraki, Tokyo, and Okayama, Japan. Each teacher was interviewed for an average of 30 minutes. Transcriptions of the interview were used in the data analysis. The statement of each science teacher was used to identify several important implications. In this study, we extracted the things that were common to 30 excellent science teachers in the country in order to build an instructional model for Japanese Science Teachers of the Gifted.

The results of the text analysis extracted some phrases that commonly described science instruction, specifically with regards to student characteristics: (1) tend to worry too much, but do not mind it; (2) childlike; (3) have a good spirit of inquiry; (4) are proud of their jobs; (5) communication; (6) set things right; (7) have an awareness of the issues in daily life; (8) words of encouragement from one's family; (9) setting one's sights high.

Themes from the teacher model include: (1) at first themes were not given to the students; (2) chances for appropriate advice and interviews were needed; (3) teachers should continue to study; (4) originality was appreciated; (5) the process and experience were more 
important than the results themselves; (6) teachers helped students to acquire basic understanding and skills; (7) study/research was similar to play for students; (8) students established good networks with experts in a specific area; (9) teachers enjoy teaching gifted students science very much; (10) students were asked to design their own research; (11) students were asked to make things; and (12) students developed the habit of recording what they thought and found in everyday life. Finally, an instructional model for Japanese science teachers of the gifted is proposed on the basis of the results herein. We propose using this model as a teaching model in high schools.

Ninety percent of the data used in constructing the teaching model in this study came from high school level teachers and students. In addition to this analysis, by performing subsequent analyses of teaching models used by practitioners of compulsory classes, we might expect qualitatively different results. Future research should also aim to expand both the breadth and points of view analyzed in order to attain a more in-depth understanding.

\section{Acknowledgement}

This work was supported by JSPS KAKENHI Grant Number 20908031, and 21908034.

\section{Supplementary Note}

Some parts of this paper were presented at the International Conference of East-Asian Association for Science Education, China in 2013.

Sumida, M., \& Yamaoka, T. (2013). Instructional Model of Japanese Science Teachers for the Gifted, EASE 2013 Conference Proceedings, 32.

\section{References}

[1] Retrieved from http://www.mext.go.jp/b_menu/kihon/about/.

[2] Matsumura, N. (2008). Grow to find true the "talent," Minerva Publishing: Japan, 48-50.

[3] Retrieved from http://event.yomiuri.co.jp/jssa/index.htm.

[4] Retrieved from http://www8.cao.go.jp/cstp/kihonkeikaku/kihon3.html.

[5] Retrieved from http://www8.cao.go.jp/cstp/kihonkeikaku/index4.html.

[6] Retrieved from http://www.jst.go.jp/pr/info/info726/besshi.html.

[7] Sumida, M. (2010). Identifying twice-exceptional children and three gifted styles in the Japanese primary science classroom. International Journal of Science Education, 32(15), 2097-2111.

[8] Retrieved from http://khc.sourceforge.net/.

[9] Higuchi, K. (2014). Toward the inheritance and development of weighing text analysis content analysis for social research: Nakanishiya publication, 1-16.

[10] Yager, R. (1991). The Constructivist Learning Model: THE SCIENCE TEACHER, 52-57. 